\title{
Paisagens através de outros olhares ${ }^{1}$
}

\section{Landscapes through other looks}

\author{
Dora Shellard Corrêa*
}

\begin{abstract}
Resumo
Neste artigo discuto a concepção de paisagem nas obras historiográficas, especialmente do último quarto de século e a questão da historicidade dessa noção. O objetivo é perceber como temos assimilado essa noção e apontar, aprofundando a discussão sobre a ideia de paisagem, os limites que essas abordagens apresentam quando nos propomos a analisar diversos tipos de documentos, numa pesquisa que enfoca a longa duração.

Palavras-chaves: Paisagem, historiografia, crítica documental
\end{abstract}

\begin{abstract}
In this article we discuss the concept of landscape in historical works, especially the past quarter century and the question of the historicity of this notion. The goal is to understand how we have assimilated this notion and point, deepening the discussion on the idea of landscape, the limits these approaches present when we undertake an analysis of various types of documents, in a survey that focuses on the long term periodization.
\end{abstract}

Key words: Landscape, historiography, source criticism.

A historiografia brasileira retorna na atualidade, como outras tantas historiografias nacionais, a observar o espaço geográfico e a paisagem. ${ }^{2} \mathrm{O}$ seu olhar sobre os cenários pretéritos apenas superficialmente é semelhante ao modo como se procedia na primeira metade do século XX, quando havia um grande entrosamento entre a história e a geografia. Os contextos históricos são completamente diversos e, também, a relevância de alguns

\footnotetext{
* Doutora em História. Trabalha na UNIFEO.E-mail: pdscor@uol.com.br

${ }^{1}$ Este artigo foi produzido como uma das atividades do projeto "As delimitações espaciais sobre a pesquisa em história ambiental”, financiado pelo CNPq - Chamada Universal 14/2012.

${ }^{2}$ Cabe esclarecer que utilizo a noção de paisagem para referir-me aos elementos naturais percebidos sensorialmente/sentidos pela visão, organizados, perspectivisados e enquadrados.
} 
conceitos articuladores das narrativas, como por exemplo, universalidade, continuidade, diversidade, descontinuidade, material, simbólico e representação. A produção atual, embora muito interessante e expressiva quantitativamente e qualitativamente, tem resultado em diálogos restritos a poucas referências, ${ }^{3}$ em especial, Simon Schama, Keith Thomas, mas também Alain Corbin, Raymond Williams e Yi-fu Tuan. ${ }^{4}$ Apesar do aprimoramento na análise crítica das fontes, tem se privilegiado alguns tipos de descrições produzidas em geral no século XIX por padres, cronistas, pintores, cientistas, políticos, induzindo involuntariamente à concepção da existência de uma quase homogeneidade na maneira de olhar, conceber e descrever ou pintar o mundo natural. Embora até se afirme a historicidade da noção de paisagem ${ }^{5}$ e das relações simbólicas das sociedades com a natureza, a maioria das pesquisas não enfocam a mudança. A produção sobre os relatos a respeito da natureza e as descrições de paisagens para os séculos XIX e XX é muito rica. Entretanto, para quem quer pensar a paisagem da América portuguesa a partir de documentos variados como crônicas, mas também relatos de sertanistas, monçoeiros, soldados, dadas de sesmarias e manuscritos administrativos e trabalhar com períodos extensos, o debate atual é insuficiente porque a sua elaboração parte de uma realidade singular, os séculos XIX e XX.

Partindo dessa constatação, meu objetivo com este artigo é entender como a historiografia tem trabalhado a noção paisagem e, ligada a ela, a de natureza. Para então problematizar a partir de uma bibliografia, além de Simon Schama e Keith Thomas, que instrumentalize a história ambiental na análise da documentação que descreve a natureza da América Portuguesa até a entrada do século XX, quando, segundo já se convencionou, era outra a forma de olhar e conceber a natureza e a própria realidade. ${ }^{6}$ A minha

\footnotetext{
${ }^{3}$ Adalmir Leonídio faz a mesma observação em: LEONÍDIO, Adalmir. 0 conceito de paisagem em história. XXV Simpósio Nacional de História - ANPUH, Fortaleza, 2009. Disponível em:< http://anpuh.org/ anais/?p=16114> acessado em 05/03/2015.

${ }^{4}$ SCHAMA, Simon. História e paisagem. São Paulo: Companhia das Letras, 1996 THOMAS, Keith. O homem e o mundo natural. São Paulo: Companhia das Letras,1989. CORBIN, Alain. 0 território do vazio. A praia e o imaginário ocidental. São Paulo: Cia das Letras, 1989. WILLIAMS, Raymond. 0 campo e a cidade. Na história da literatura. São Paulo, Cia das Letras, 2000. TUAN, Yi-fu. Paisagens do medo. São Paulo: Unesp, 2005.

${ }^{5}$ Vide por exemplo: SCHWARCZ, Lilia Moritz. Paisagem e identidade. A construção de um modelo de nacionalidade herdado. Acervo. Rio de Janeiro, v. 22, n. 1, p. 19-52, jan/jul 2009.

${ }^{6}$ São vários trabalhos que abordam essa questão de diferentes ângulos. Por exemplo, no Brasil o clássico Visão do Paraiso de Sérgio Buarque de Holanda. HOLANDA, Sérgio Buarque. Visão do Paraíso. Os motivos edênicos no descobrimento e colonização do Brasil. 5ª ed. São Paulo: Brasiliense, 1992. Um estudo relativamente recente feito nos EUA é Os olhos do Império de Mary Louise Pratt. PRATT, Mary Louise. Os olhos do império. Relatos de viagem e transculturação. Bauru: Edusc, 1999.
} 
proposta é que o historiador analise as descrições do visualizado e das formas retratadas, bem como o quadro todo tendo em conta sua historicidade. ${ }^{7}$ Não penso somente na historicidade da ideia de paisagem e das representações atreladas, mas também das formas percebidas. Embora essa proposição pareça óbvia, como defenderei mais à frente, em geral não tratamos as formas.

Cabe, nesta introdução, justificar porque considero pertinente ater-me à discussão da paisagem descrita em documentos, enquanto que muitos historiadores ambientais têm defendido o uso da observação direta do espaço geográfico. Traçar a ocupação e exploração pretérita da natureza pode ser feito através de trabalho de campo. Contudo, tais investigações são incompletas para a compreensão do porquê de uma técnica, de um produto e de dada conformação espacial de períodos tão distantes quanto os séculos XVI, XVII e XVIII, caso também existam outros tipos de testemunhos. Expõe uma prática, mas não o pensamento e a circunstância que a gerou. O entendimento das relações passadas através dos modos de visualização do espaço geográfico e da natureza possibilitam, também, a crítica de mitos presentes como, por exemplo, da objetividade do nosso olhar científico quando apoiado diretamente na realidade percebida. A conjunção, quando possível, do trabalho de campo com a análise de diferentes formas e suportes de narrativas pela qual uma sociedade se manifesta seria o perfeito em história ambiental. ${ }^{8}$ Porém, não se deve minimizar a complexidade de tal sugestão. Mesmo que o tema seja paisagem, o indício que se analisa no trabalho de campo não é o mesmo que o da pesquisa documental.

Para discutir paisagem se deve, num primeiro momento, esclarecer-se o tipo de evidência que é objeto de análise: o quadro natural diretamente visualizado pelo pesquisador no trabalho de campo ou documentos escritos, dados quantitativos, fotografias, pinturas ou filmes que descrevem ou sugerem um cenário. Esses testemunhos se caracterizam por serem heterogêneos modos de representação do real. Por um lado, há de se constatar que a representação não se trata de um simples reflexo, mas contém mais do que o real. Segundo Henry Lefebvre ela é composta tanto por mitos antigos, juízos de

\footnotetext{
${ }^{7}$ Segundo Agnes Heller historicidade é tempo e espaço. HELLER, Agnes. Uma teoria da história. Rio de Janeiro: Civilização Brasileira, 1981.

${ }^{8}$ Sobre essa proposição vide o artigo:

OLIVEIRA, Rogério Ribeiro de; ENGERMAN, Carlos. História da paisagem e paisagens sem história. A presença humana na floresta atlântica do sudoeste brasileiro. Esboços. Florianópolis, v. 8, n. 25, p. 9-31, ago. 2011.
} 
valor, necessidades presentes, como elementos que se conseguem com certa facilidade distinguir a representação do representado. Por outro lado, deve se ter em conta que entre o testemunho e a sua análise pelo pesquisador, há o tempo do protagonista da descrição, da fotografia ou da pintura, bem como do próprio investigador. Enfim, teoricamente e metodologicamente esses diferentes documentos demandam procedimentos diversos. ${ }^{9}$ Este artigo polemiza sobre a análise das fontes escritas e propõe uma prática.

Embora já se tenha publicado artigos interessantes e pertinentes apresentando um panorama da noção de paisagem na produção historiográfica em geral e na história ambiental em particular, ${ }^{10}$ tem-se preterido considerar os métodos para a análise dos diferentes tipos de fontes escritas utilizadas pelo pesquisador em sua investigação, bem como a historicidade da própria noção. Cabe esclarecer que não se trata de uma deficiência, mas de que tais pesquisadores, como faço agora, estão buscando instrumentalizar sua própria pesquisa.

Este artigo está dividido em três partes. Na primeira - Historiografia e a paisagem - discuto a produção historiográfica elaborada na primeira metade do século XX, considerada como raíz da historiografia atual quanto ao seu enfoque do meio ambiente e paisagem. ${ }^{11} \mathrm{Na}$ segunda - História ambiental e história cultural - contrasto a história ambiental e a cultural e polemizo sobre a influência da historiografia da primeira metade do século $\mathrm{XX}$ sobre esses dois campos. Por último - Construindo a paisagem - proponho

\footnotetext{
${ }^{9}$ Jean Marc Besse propõe que o cenário natural selecionado, ordenado e visualizado pelo pesquisador, a paisagem segundo ele, deve ser lida. Tal afirmação não implica em adotar os mesmos procedimentos que se tem com relação à análise do documento escrito.

${ }^{10} \mathrm{Um}$ dos artigos mais completos, que apresenta uma relação de autores e especialmente de discussões que se tem hoje sobre paisagem desenvolvidas pela geografia, história e turismo é: MENEZES, Ulpiano T. Bezerra de. A paisagem como fato cultural. In: YAZIGI, Eduardo (org.). Turismo e paisagem. São Paulo: Contexto, 2002. p. 29-64.

Vale mencionar também:

OLIVEIRA, Rogério; MONTESUMA, Rita de Cássia. História ambiental e ecologia da paisagem.

Mercador.Fortaleza, UFC, v. 9, n. 19, p. 117-128, 2010

Francisco Carlos Teixeira da Silva: SILVA, Francisco Carlos Teixeira. História das paisagens. In: CARDOSO, Ciro Flamarion; VAINFAS, Ronaldo. Domínios da história. Ensaios de teoria e metodologia. Rio de Janeiro: Campus, 1997. p. 203-216.

KAPINSKI, Cezar. Paisagem e história. Revista Espaço Plural. Cascavel,V. 12, n. 25,p. 26-36, 2011. Disponível em: < http://e-revista.unioeste.br/index.php/espacoplural/issue/view/468/showToc> Acessado em $14 / 03 / 2015$.

LEONÍDIO, Adalmir. O conceito de paisagem em história. XXV Simpósio Nacional de História - ANPUH, Fortaleza, 2009. Disponível em:< http://anpuh.org/anais/?p=16114> acessado em 05/03/2015.

CORRÊA, Dora Shellard. História ambiental e a paisagem. HALAC. Belo Horizonte, v. II, n. 1, sitiembre-febrero 2013, p. 47-60.

${ }^{11}$ DUARTE, Regina Horta. História \& Natureza. Belo Horizonte: Autêntica, 2005.
} 
o tratamento da noção de paisagem apoiada em intelectuais pouco visitados por nossa historiografia.

\section{Historiografia e a paisagem}

Angelo Torre, em artigo publicado em 2008 nos Annales, ${ }^{12}$ chamou a atenção para o fato de que muitos historiadores estavam se debruçando sobre um novo tema, as paisagens pretéritas. Para além de um modismo, discutir paisagem na atualidade se justifica numa época em que começam a tomar a nossa imaginação cenários virtuais, micro celulares, distantes dos quadros bucólicos ou das descrições geográficas, mas que traçam formas que parecem tão reais e subjetivas quanto aquelas. ${ }^{13}$ Quando crescentemente os movimentos migratórios pelo globo vêm envolvendo massas enormes de populações que avançam para países vizinhos, para campos de refugiados, que em famílias ou individualmente mudam de continente, estabelecem-se em antigas metrópoles, construindo novos cenários, novas paisagens, carregando as antigas na memória. ${ }^{14}$ Em que projetos urbanísticos, guerras, fenômenos naturais destroem cidades que são reconstruídas ou permanecem em ruínas. Num momento em que entidades nacionais e internacionais científicas e políticas fixam paisagens como patrimônio transformando-asem monumentos. Quando preservamos espaços geográficos afirmando seu relevante interesse ecológico e paisagístico. Quando se busca universalizar a ideia ocidental de paisagem como as formas naturais e construídas que visualizamos, ao mesmo tempo que há uma grande pressão pelo direito, reconhecimento e respeito às diversidades. E, finalmente, no momento em que o turismo e a indústria ${ }^{15}$ descobrem a paisagem como um bem a ser comercializado.

\footnotetext{
${ }_{12}$ TORRE, Angelo. Un tournant spatial en histoire ? Paysages, regards, resources. Annales. Histoire, Sciences socials. Paris, n. 5, p. 1127 - 1144, 2008.

${ }^{13}$ Anne Couquelin chama a atenção para o fato de que o mundo digital levará possivelmente a uma transformação de nossa concepção de paisagem. CAUQUELIN, Anne. A invenção da paisagem. São Paulo: Martins Fontes, 2007.

${ }^{14}$ Barbara Bender chama a atenção para o fato dos migrantes carregarem suas paisagens em suas migrações. BENDER, Barbara. Introduction. BENDER, Barbara; WINER, Margot (Ed.) Contested landscapes. Movement, exile and place. Oxford: Berg, 2001. p. 1-18. O livro é constituído por uma série de artigos de vários antropólogos, arqueólogos, geógrafos, literatura, proferidos numa reunião de arqueólogos na África do Sul em 1999. Foi uma forma de "de tentar entender como as pessoas num mundo turbulento criam o senso de lugar e pertencimento, de perda ou negação" (BENDER; WINER, 2001, p1)

${ }^{15}$ Uma observação pertinente quanto a associação da água à mercadoria foi feita por Bianc-Pomard e Raison no final do milênio. Segundo eles: "Dentro em pouco não haverá água mineral sem uma etiqueta embelezada por uma paisagem agreste e de preferência montanhosa".

BIANC-POMARD, Chantal; RAISON, Jean Pierre. Paisagem. In: ENCICLOPÉDIA EINAUDI. Região. 8. Porto: Imprensa Nacional; Casa da Moeda, 1986. p. 158.
} 
A Terra e o Brasil em particular possibilitam inúmeras paisagens retratadas em pinturas como em Nicolas Antoine Taunay, Joseph Mallord William Turner, Jean Baptiste Debret, descritas em ficções como em Josep Conrad, José de Alencar, escritas e ilustradas em livros de exploradores como David Livingstone, de cientistas como John Henning Richard Burton, investigadas e tipificadas nas obras de geógrafos como Paul Vidal de la Blache, Pierre Monbeig, Carl Sauer, Aroldo de Azevedo, descritas na história por Capistrano de Abreu, Marc Bloch, Fernand Braudel. No livro Dois irmãos, de Milton Hatton, imaginamos uma Manaus ocupada por imigrantes árabes tão minuciosamente descritos que possibilita associar também outro sentido à imagem, o odor das árvores tropicais. O humanista Raymond Williams, em seu livro Campo e Cidade, nos narra o que ouve naquele exato momento em que olha pela janela e nos permite penetrar na imagem a que o som o remete. Euclides da Cunha, em Os Sertões, nos leva a uma paisagem que envelhece como se fosse um ser humano. Henry David Thoreau em Walden ou A vida nos Bosques defende que a paisagem transmite uma sensação de alegria e Yi-Fu Tuan em Paisagens do Medo fala de paisagens que suscitam a consciência do sentimento de perigo. Os historiadores e geógrafos brasileiros, com poucas exceções, até o último quarto de século XX, descreviam o interior da América portuguesa e depois a fronteira demográfica do estado nação como marcadas por uma paisagem virgem ou quase virgem.

Estes dois parágrafos acima evidenciam os inúmeros sentidos dados à noção paisagem em nosso cotidiano. Assim como expõem o movimento entre definições que afirmam sua objetividade, bem como sua subjetividade. Ambiguamente é utilizada tanto para denotar o cenário que foi produzido através de uma prática local e que reconhecemos através do trabalho de campo, como um conjunto de elementos naturais avistados por um observador e o seu registro por meio de diferentes linguagens e suportes.

Essa multiplicação de definições do conceito e a constatação sobre a sua ambiguidade ou polissemia são fenômenos presentes. A afirmação de Lilia Moritz Schwarcz em seu livro 0 sol do Brasil, publicado em 2008, de que o "olhar que estabelece a diferença entre essência (como natureza) e paisagem (como representação)" 16 serve como ilustração de tal fato. Essa é uma primeira singularidade da produção atual sobre paisagem e os temas hoje correlatos, natureza e meio ambiente.$^{17}$ As obras historiográficas publicadas

\footnotetext{
${ }^{16}$ SCHWARCZ, Lilia Moritz. 0 sol do Brasil. Nicolas Antoine Taunay e as desventuras dos artistas franceses na corte de d. João. São Paulo: Cia das Letras, 2008. p. 125.

${ }^{17}$ Anne Cauquelin aponta natureza e meio ambiente como utilizados na atualidade como correlatos à paisagem. CAUQUELIN, op. cit. .
} 
até o último quarto do século que descreveram cenários naturais pretéritos, não polemizavam sobre a essência tanto da percepção quanto do conceito.

As descrições do espaço físico onde os fatos e processos se davam já estão presentes desde a metade do século XIX na História Geral do Brasil de Adolfo Varnhagem. Porém, aí se encontra uma caracterização geográfica que fragmentava o Brasil, enumerando alguns recursos naturais e impossibilitando a imaginação de um cenário geral. A única grande síntese visual que produz se resume ao fato de retratar o território nacional demarcado por três elementos naturais: o rio Amazonas, a bacia do Prata e o Oceano Atlântico. Uma caracterização de Brasil com a qual muitos brasileiros letrados da época talvez não se identificassem. Foi a partir da entrada do século XX, com Capistrano de Abreu, que se formulou um modelo de exposição da natureza e ocupação da América portuguesa e que se propôs temas que implicavam na descrição do meio natural. Nesse retrato, o rio São Francisco toma um vulto central, como exemplo de brasilidade, o rio que nasce no Brasil, atravessa o interior do nordeste, drenando uma área de mais de $640.000 \mathrm{~km}^{2}$ e deságua no Atlântico. O sertão, uma representação espacial, ${ }^{18}$ é apresentado como elemento característico do território e do povo, mas que é sempre mirado de longe, não penetrado pelo historiador. ${ }^{19}$ Um espaço geográfico caracterizado pelo historiador cearense como quase virgem e vazio demograficamente. A partir da década de 1930, Caio Prado Júnior, embora por uma linha teórica e metodológica distinta, segue Capistrano esboçando a paisagem a partir do litoral avançando para o interior, invadido pelos colonos e aí estancando na boca do sertão. Desse ponto à fronteira política a descrição é sumária. Uma generalização que revela apenas o seu cerne idealizado.

Gilberto Freyre e Sérgio Buarque de Holanda, também a partir da década de 1930, debruçam-se sobre o espaço geográfico. O primeiro em Nordeste, segundo ele mesmo uma tentativa de estudo ecológico, observa a relação do

\footnotetext{
${ }^{18}$ Ulpiano Bezerra aponta que o sertão como o wilderness norte americano são paisagens. Sertão é um conceito que teve seu sentido alterado ao longo do tempo e espaço. Remetia, no sul e sudeste da colônia portuguesa, nos séculos XVI ao início do XIX, mais à soberania política, intelectual e material de uma área do que às formas da natureza. $O$ tratamento do sertão como uma paisagem parece ter sido estabelecido pela historiografia a partir do final do século XIX. Sobre esse assunto vide: CORRÊA, Dora Shellard. Paisagens sobrepostas. Índios, posseiros e fazendeiros nas Matas de Itapeva (1723-1930). Londrina: Eduel, 2014. MENEZES,. op. cit. p. 29-64.

${ }^{19}$ Sobre a noção de sertão no pensamento social brasileiro vide: LIMA, Nísia Trindade. Um sertão chamado Brasil. Intelectuais e representação geográfica da identidade nacional. Rio de Janeiro: Renavan; IUPERJ, UCAM, 1999. OLIVEIRA, Lúcia Lippi. A conquista do espaço. Sertão e fronteira no pensamento brasileiro. In: _______ Americanos. Representações da identidade nacional no Brasil e nos EUA. Minas Gerais: UFMG, 2000. p.69-126.
} 
colonizador canavieiro com a terra e sua influência na vida e na paisagem do nordeste. Produz uma regionalização do Brasil, circunscrevendo o Nordeste e dentro deste a Zona da Mata e o Sertão, este termo designando o semiárido. Diferentemente dos demais intelectuais, há uma personificação da natureza, produzindo um efeito estilístico interessante, mas ideologicamente despolitizando as descrições. Mostra como as relações sociais se impuseram sobre a própria maneira de conceber a paisagem, deformando ou moldando e qualificando o visualizado. Sérgio Buarque de Holanda penetra no sertão e o descreve por dentro em Monções, Caminhos e Fronteiras e 0 extremo oeste, bem como, analisa as projeções do mito sobre o Éden na conformação das descrições da colônia nos seus primeiros séculos.

Nas décadas de 1950 e diminuindo posteriormente, observa-se uma produção elaborada dentro das jovens universidades brasileiras em São Paulo e no Rio de Janeiro sob grande influência francesa, especialmente dos Annales. São representativas desse momento, entre inúmeros outros, Maria Yedda Linhares (UFRJ), Alice Piffer Canabrava (USP) e Maria Thereza Petrone (USP). Embora Warren Dean ${ }^{20}$ tenha atentado para o fato de que os historiadores brasileiros, nesse momento, estavam mais preocupados em discutir o desenvolvimento do país através da análise de suas estruturas sociais e econômicas, as descrições sobre o processo de exploração e apropriação da terra permaneceram, ainda que discretamente. Gilberto Freyre mostrou como uma dada forma de ocupação por um grupo social impõe uma qualificação ou desqualificação de um dado cenário. Sérgio Buarque de Holanda, no final da década de 1950 em Visão do Paraiso, apontou que as descrições da natureza constantes dos documentos dos dois primeiros séculos da colonização, fossem eles relatórios oficiais ou crônicas, eram influenciados pela imagem edênica difundida na época dos descobrimentos marítimos. Apesar dessas obras os historiadores que se debruçavam sobre o espaço físico, continuaram a tratar as paisagens e os elementos naturais retratados na documentação histórica como réplica do real.

A historiografia brasileira, a partir da década de 1990, não só retornou a invocar cenários pretéritos como contrastando ao que era comum até a década de 1950, elegeu paisagem e, associada a esta noção, meio ambiente e, mais recentemente, patrimônio como temas singulares. ${ }^{21}$ Apesar desse

\footnotetext{
${ }^{20}$ DEAN, Warren. With broadax and firebrand. The destruction of the Brazilian Atlantic Forest. Berkeley: University of California Press, 1995.

${ }^{21}$ Um artigo sobre história da paisagem como uma especialidade historiográfica foi escrito por Francisco Carlos Teixeira da Silva: SILVA, Francisco Carlos Teixeira. História das paisagens. In: CARDOSO, Ciro
} 
movimento expressivo quantitativamente, não se chegou a constituir no Brasil uma especialidade historiográfica. ${ }^{22} \mathrm{O}$ que se tem observado é a sua inserção como um recorte temático, um foco de atenção dentro de alguns campos, como da história cultural, da arte e ambiental. ${ }^{23}$

\section{História ambiental e história cultural}

Nesse final do século XX, a historiografia brasileira se transformou seguindo, sem espelhar totalmente, a Nova História francesa, instigada como ela pelas mudanças de paradigmas dentro das ciências humanas. A atenção à narrativa volta a se sobrepor à análise como chamaram a atenção Fernando Novais e Rogério R. da Silva. ${ }^{24}$ Metodologicamente a ideia de representação ${ }^{25}$ torna-se central. Mas alguns historiadores alertam sobre como essa noção e outras como paisagem têm sido utilizadas de maneira transigente, talvez fruto da ideia de que a precisão não coaduna com a boa narrativa. ${ }^{26} \mathrm{Ou}$ talvez sigam, no caso da noção de paisagem, Chantal Bianc-Pomard e Jean Pierre Raison que afirmam ser um "vocábulo polissêmico, e cada um de nós deveria explicar o que entende por paisagem". ${ }^{27}$

Flamarion; VAINFAS, Ronaldo. Domínios da história. Ensaios de teoria e metodologia. Rio de Janeiro: Campus, 1997. p. 203-216.

${ }^{22}$ Francisco Carlos Teixeira da Silva em artigo definiu a história da paisagem. Contudo, ele se limita, em grande parte, às análises de descrições elaboradas pela história econômica e por uma história ambiental que estava no seu início. No novo milênio houve um crescente interesse por esse tema, paisagem, pela história cultural e por uma história ambiental mais amadurecida. Vide: SILVA, op. cit.

${ }^{23}$ Ulpiano Bezerra, criticando os artigos apresentados em livro resultado do I Colóquio Internacional de História da Arte Paisagem e arte, observa a indefinição no uso do conceito paisagem e o perigo de sua desistorialização. Vide: BEZERRA, Ulpiano. Balanço crítico. SALGUEIRO, Heliana Angotti (Org.) Paisagem e arte. A invenção da natureza, a evolução do olhar. São Paulo: CDBHA; FAPESP; Brasília: CNPq, 2000, p. 431-437

${ }^{24}$ NOVAIS, Fernando Antônio; SILVA, Rogério Forastieri da. Introdução . In: (org.) Nova história em perspectiva. São Paulo: Cosacnaiffy, 2011. p. 7-70.

${ }^{25}$ Cabe lembrar que discutir representação é outra polêmica. Dizer que ela contém mais do que o representado está longe de esclarecer o que a compõe. Duas definições diferentes estão em Chartier e Lefebvre: CHARTIER, Roger. O mundo como representação. Estudos Avançados. São Paulo, USP, v. 5, n. 11, 1991, p.173-191. Disponível em: http://www.scielo.br/scielo.php?script=sci_arttext\&pid=S0103$-40141991000100010 \& \operatorname{lng}=e n \& n r m=i s o$ acessado em 21/03/2015. LEFEBVRE, Henri. La presencia y la ausencia. Contibuición a la teoria de las representaciones. México: Fondo de Cultura Económica, 2006.

${ }^{26}$ Ulpiano Bezerra faz esse comentário sobre os trabalhos apresentados em congresso sobre paisagem e arte. Ele refere-se especialmente a aqueles artigos, porém é procedente expandi-lo para a produção historiográfica brasileira. Já apontei atrás que Adalmir Leonídio critica a falta de rigor dos historiadores no emprego da noção de paisagem. Vide: BEZERRA, Ulpiano. Balanço crítico. SALGUEIRO, Heliana Angotti (Org.) Paisagem e arte. A invenção da natureza, a evolução do olhar. São Paulo: CDBHA; FAPESP; Brasília: CNPq, 2000, p. 431-437. LEONÍDIO, op. cit.

${ }^{27}$ BIANC-POMARD, Chantal; RAISON, Jean Pierre. Paisagem. In: ENCICLOPÉDIA EINAUDI. Região. 8. Porto: Imprensa Nacional; Casa da Moeda, 1986. p. 138. 
Concomitantemente, como indicou Ciro Flamarion Cardoso, ${ }^{28}$ houve um aprofundamento na análise documental, um retorno à hermenêutica. Observa-se a intensificação de estudos que se restringem à crítica dos testemunhos. Esse intelectual critica essa redução da história à crítica documental, afirmando que tal postura metodológica resulta na negação do caráter científico, objetivo e racional da história. ${ }^{29}$

Nesse contexto, a descrição do espaço físico recupera superficialmente o estilo das abordagens da primeira metade do século XX. A paisagem volta a ser caracterizada, confundindo-se agora com as noções de natureza e de meio ambiente. Se a terra a e sua exploração era afirmada, num primeiro momento, como suporte da brasilidade, ${ }^{30}$ depois como recurso de produção, ${ }^{31}$ hoje é meio ambiente, natureza, mas também, representação. ${ }^{32}$ A realidade investigada que tinha como referência o nacional se fragmenta cedendo para o enfoque do fenômeno local e regional em suas peculiaridades. Mas também se observam estudos que ultrapassam em muito esse perímetro. Em alguns casos, o foco territorial de análise deixa até de obedecer às fronteiras nacionais e passa a ser determinado pelo tema estudado: 0 império português, o comércio transatlântico, as sociedades indígenas na

\footnotetext{
${ }^{28}$ CARDOSO, Ciro Flamarion. Introdução. História e paradigmas rivais. In: ; VAINFAS, Ronaldo. Domínios da história. Ensaios de teoria e metodologia. Rio de Janeiro: Campus, 1997. p. 1-23.

${ }^{29}$ CARDOSO, op. cit..

${ }^{30}$ Vide: GUIMARÃES, Manuel Luís Salgado. Historiografia e nação no Brasil. 1838-1857. Rio de Janeiro: UERJ, 2011. Especialmente o capítulo 3.

${ }^{31}$ Um exemplo é: PRADO JÚNIOR, Caio. Formação do Brasil contemporâneo. 14". ed. São Paulo: Brasiliense, 1976. Esse livro influenciou expressivamente as gerações até a década de 1980.

${ }^{32}$ Entre as coletâneas de história ambiental cabe mencionar: ARRUDA, Gilmar. (Org.) Natureza, fronteiras e territórios. Londrina: Eduel, 2005. KLANOVICZ, Jó; ARRUDA, Gilmar; CARVALHO, Ely Bergo. (Orgs.) História ambiental no sul do Brasil. Apropriações do mundo natural. São Paulo: Alameda, 2012. NODARI, Sueli Nodari; KLUG, João. (Orgs.) História ambiental e migrações. São Leopoldo: Oikos, 2012. PEREIRA, Elenita Malta; RUCKERT, Fabiano Quadros; MACHADO, Neli Galarce. (Orgs.) História ambiental no Rio Grande do Sul. Lajeado: Univates, 2014. FRANCO, José Luiz de Andrade; SILVA, Sandro Dutra e; DRUMMOND, José Augusto; TAVARES, Giovana Galvão. (Orgs) História ambiental. Fronteiras, recursos naturais e conservação da natureza. Rio de Janeiro: Garamond, 2012. A exceção da última, todas as demais têm pelo menos um artigo em que a questão é discutir a paisagem enquanto uma representação do visualizado e não a natureza ou meio ambiente como uma concretude apropriada e explorada. No caso de obras que discutem a representação da paisagem cabe ressaltar as seguintes: ASSUNÇ̃̃O, Paulo de. A "Terra dos Brasis". A natureza da América Portuguesa vista pelos primeiros Jesuítas (1549-1596). São Paulo: Annablume, 2001. DIAS, Elaine. Paisagem e academia. Felix-Émile Taunay e o Brasil (1824-1851). Campinas: Unicamp, 2009.

LISBOA, Karen Macknow. A Nova Atlântica de Spix e Martius: natureza e civilização na Viagem pelo Brasil (1817-1820). São Paulo: Hucitec; FAPESP, 1997. MURARI, Luciana. Natureza e cultural no Brasil (1870-1922). São Paulo: Alameda, 2009. NAXARA, Márcia Regina Capelari. Cientificismo e sensibilidade romântica. Em busca de um sentido explicativo para o Brasil no século XIX. Brasília: UNB, 2004. SCHWARCZ, Lilia Moritz. 0 sol do Brasil. Nicolas Antoine Taunay e as desventuras dos artistas franceses na corte de d. João. São Paulo: Cia das Letras, 2008.
} 
América do Sul, a mata Atlântica. As identidades se multiplicam e diversificam: nacional, de classe, de gênero, brasileiro, Kaiowá, Caingang e Ashanti. O diálogo é ampliado para a antropologia, literatura e também para além das ciências humanas, para a geografia física, biologia e ecologia.

Partindo dessas constatações, torna-se pertinente expor sinteticamente como a história cultural e a ambiental no Brasil têm enfocado o tema paisagem. Esses campos contrastam aqui não tanto pelo significado dado à noção - concebe-se paisagem tanto quanto uma percepção, como uma concretude ou uma representação -, mas pelo predomínio, no caso do primeiro, de perspectivas que desprezam a relação entre a representação e o objeto real representado, os elementos naturais e, no segundo prevalece a consideração à realidade material. Ou seja, enquanto no primeiro caso se permanece no aprofundamento da representação, no outro se considera paisagem um conjunto pré-existente ao pensamento e se aprofunda na forma enquanto uma concretude.

Algumas obras tanto em história ambiental como cultural expõem claramente ou deixam subtendidas suas reflexões sobre a paisagem. Problematiza-se sobre as mediações entre o sujeito e o objeto visualizado; o que determina e intervém objetivamente na organização desses elementos naturais visualizados, o que é uma representação e o que a conforma.

Os historiadores ambientais formados em História no Brasil, em geral com doutoramento em História econômica e social ou cultural, ${ }^{33}$ apoiam-se teórica e metodologicamente nos debates que esses campos proporcionam. Porém, distinguem-se por, na sua quase totalidade, se reportarem ou criticarem o discurso e prática atual de apropriação e exploração do meio ambiente. Muitas pesquisas têm um caráter pragmático, buscando fornecer subsídios para o desenvolvimento de políticas públicas, promoção de ações ou desmistificação de concepções presentes ou pretéritas sobre a natureza e sua apropriação e exploração. A afirmação de Jean-Marc Besse de que aqueles que têm como objetivo intervir no território buscam ir além das representações, embora se referindo à intelectualidade em termos globais, também cabe à essa produção brasileira. ${ }^{34}$

\footnotetext{
${ }^{33}$ São recentes os cursos de pós-graduação e mesmo graduação em História que discutem História Ambiental.

${ }^{34}$ BESSE, Jean-Marc. A fisionomia da paisagem, de Alexander Humboldt a Paul Vida de La Blache. In: Ver a terra. Seis ensaios sobre a paisagem e a geografia. São Paulo: Perspectiva, 2006. p. 61-74.
} 
Os historiadores ambientais são, em sua boa maioria, pessoas que se reportam à questão ambiental, ${ }^{35}$ ou seja, têm muito claro um dos aspectos políticos de seu trabalho, o qual comporta um projeto que envolve, seja a conservação, a preservação e a transformação das formas de exploração dos recursos naturais, ou da relação dos homens e mulheres com a terra. Heterogêneos quanto às teorias e metodologias de abordagem, encontramos entre eles tanto os que defendem a busca da universalidade, quanto os que defendem a diversidade, os que procuram continuidades e aqueles que acentuam as descontinuidades. Unem-se na discussão da questão ambiental, mas distanciam-se em sua postura política e, portanto, teórica e metodológica.

O que se observa entre os historiadores ambientais é tanto uma concepção "realista" como "culturalista" sobre a paisagem, seguindo a definição de Jean Mac Besse. ${ }^{36}$ No caso da primeira, paisagem é o visualizado, mediada ou não pela cultura. A paisagem é o reflexo do trabalho humano sobre a terra, das formas de exploração dessa terra. Essa definição é instrumental, particularmente para quem investiga uma documentação mais recente e fundamentalmente para quem produz estudos com uma finalidade pragmática e não exclusivamente acadêmica. Enquanto a segunda trabalha com a concepção de que paisagem é um fato cultural, formas que só existem quando percebidas, significadas e representadas pelos homens.

Os historiadores que se envolvem com a história cultural têm se engajado no estudo das pinturas de paisagem, ${ }^{37}$ das descrições da literatura ${ }^{38}$ e discutido como os homens de outras épocas viam a natureza brasileira. ${ }^{39}$ Definem paisagem como um fato cultural, como resultado de uma ação cognitiva ou têm investigado como determinadas paisagens tornam-se espaços de admiração. ${ }^{40}$ Passam de largo à polêmica sobre as externalidades,

\footnotetext{
${ }^{35}$ A expressão "questão ambiental" está sendo empregada como os distúrbios causados pelas transformações que vem sendo processadas no meio ambiente fruto das formas de exploração da terra e dos recursos naturais na atualidade.

${ }^{36}$ BESSE, op. cit., p. 61-74.

${ }^{37}$ SCHWARCZ, op. cit. DIAS, Elaine. Paisagem e academia. Felix-Émile Taunay e o Brasil (1824-1851). Campinas: Unicamp, 2009.

${ }^{38}$ MURARI, op. cit. NAXARA, op. cit..

${ }^{39}$ ASSUNÇÃO, Paulo de. A "Terra dos Brasis". A natureza da América Portuguesa vista pelos primeiros Jesuítas (1549-1596). São Paulo: Annablume, 2001; LISBOA, Karen Macknow. A Nova Atlântica de Spix e Martius: natureza e civilização na Viagem pelo Brasil (1817-1820). São Paulo: Hucitec; FAPESP, 1997.

${ }^{40}$ SCHOSSLER, Joana Carolina. Do território do vazio ao lugar de veraneio: paisagem e cultura balneária no litoral do Rio Grande do Sul. In: KLANOVICZ et al (Orgs.), op. cit.
} 
se existe algo de material e real além dos quadros, romances, diários e cartas, além de pinturas e palavras.

Contudo, esta é uma síntese muito simplista, ainda que instrumental, acreditar-se em apenas dois enfoques de paisagem: um realista e outro culturalista. Dentro de cada uma há inúmeros aspectos divergentes. Essa situação não é singular da historiografia brasileira e nem da produção historiográfica mundial. $\mathrm{O}$ arqueólogo inglês Richard Muir escreveu um livro expondo os inúmeros enfoques dados à noção de paisagem fixadas pela geografia, história, antropologia, história da arte e outras áreas do conhecimento ${ }^{41}$ Porém, é interessante anotar que, muitos historiadores brasileiros, particularmente culturais, desconsideram qualquer relação entre a representação e o representado.

Dentro do grupo que enfoca paisagem como um fato cultural, sejam historiadores culturais ou ambientais, Simon Schama se tornou uma referência obrigatória no final do milênio, bem como uma inspiração quando se perscruta os significados de determinados conjuntos naturais visualizados a partir do século XIX. Keith Thomas é citado quando o objetivo é discutir a atitude frente à natureza e dentro de alguns conjuntos naturais como as matas. Alain Corbin, quando se quer estudar a sensibilidade em relação a um elemento natural e seu usufruto. Raymond Williams, quando se discute rural e urbano ou o mundo natural a partir da literatura. Outros como a filósofa Anne Cauquelin e o geógrafo Yi-Fu Tuan, como os demais, com seus livros sobre paisagem traduzidos no Brasil, são citações menos constantes. Mas, cabe alertar, essa é uma síntese incompleta. Encontramos estudos que, para pensar rapidamente sobre essa noção, se apoiam, por exemplo, em intelectuais que não estão discutindo diretamente a paisagem ou a natureza, como Michel Foucault, Pierre Bourdieu e Edward Said. ${ }^{42}$

Como já foi apontado, a historiografia atual só em parte se apoia nos intelectuais da primeira metade do século. Esse fato é confirmado pela leitura que muitos fazem hoje, por exemplo, de Visão do Paraíso. Na década de 1950, Sérgio Buarque de Holanda revelava como os mitos geográficos conformavam as representações do visualizado. Mas, diferentemente da maneira como processam hoje muitos historiadores culturais, não parou aí, mostrando também que tais adequações não estavam de todo desligadas do

\footnotetext{
${ }^{41}$ MUIR, Richard. Approaches to landscape. London: Macmillan Press Ltd, 1999.

${ }^{42}$ FOUCAULT, Michel. As palavras e as coisas. 3a. ed. São Paulo: Martins Fontes, 1985; BOURDIEU, Pierre. O poder simbólico. São Paulo: Difel, 1989;

SAID, Edward W. Cultura e imperialismo. São Paulo: Cia das Letras, 1999.
} 
real concreto. Ou seja, buscava-se, na realidade visualizada, elementos que se acomodassem mais facilmente aos mitos. Concebia uma realidade percebida pelo cronista, mas filtrada pelas tradições. Não eram apenas idealizações. Segundo ele: "os descobridores, povoadores, aventureiros, os que muitas vezes vêm buscar e acabam encontrando nas ilhas e terra firme do Mar Oceano é uma espécie de cenário ideal, feito de suas experiências, mitologias ou nostalgias ancestrais". ${ }^{43}$ Porém, no caso dos testemunhos portugueses utilizados, a sedução de tais motivos é comparativamente reduzida à dos espanhóis. "São razões menos especulativas, em geral, ou fantásticas, do que propriamente paradigmáticas, o que incessantemente inspira aqueles cronistas, ainda quando, em face do espetáculo novo, chegam a diluir-se em êxtases enamorados". ${ }^{44}$

Portanto, a produção atual se aproxima e se distancia em vários aspectos daquelas obras da primeira metade do século. Há hoje, como acontecia, livros que enfocavam a paisagem como uma realidade observada e transcrita, bem como uma representação. Esta última noção tanto empregada no seu sentido de uso comum, ou seja, uma cópia do real, como aquilo que contém muito mais do que o representado. Porém, mesmo no último caso, estava subtendida a existência de uma realidade, de uma exterioridade, da qual o pesquisador poderia se aproximar. Tal situação pode ser observada em Visão do Paraíso de Sérgio Buarque de Holanda. Ao analisar as crônicas e histórias dos primeiros séculos da colonização portuguesa, Sérgio Buarque argumenta que em se tratando dos aspectos climáticos, tais cronistas reverberavam para a costa baiana o clima que nos textos medievais e renascentistas caracterizava o Paraíso. Inclusive a ordem do enunciado era reproduzida: "em si de muitos bons ares, assim frios e temperados". ${ }^{45}$ Contudo, mostra que essa construção se adequava às condições climáticas reais. Eles chegavam em abril, quando o clima é mais agradável na costa nordestina. Hoje é comum se encontrar obras que se esgotam na análise da representação, induzindo a ideia de que não há nada além dela.

Distancia-se também a produção atual por, no caso da história ambiental, estarem engajados num debate que a partir do início dos anos 1970, vai obtendo maior visibilidade, seja pela crescente degradação ambiental, seja pelo processo de globalização que nos permite tomar conhecimento

\footnotetext{
${ }^{43}$ HOLANDA, op cit. p. 315 ,

${ }^{44}$ Ibidem

${ }^{45}$ Ibidem, p. 299.
} 
dos desastres ambientais ocorridos em qualquer canto do planeta, seja pela atuação das agências multilaterais que têm buscado homogeneizar as políticas nacionais em relação aos recursos naturais. Não se trata somente do aumento da exposição do tema, mas também da sua espetacularização. Tal fato, como mostra o geógrafo Carlos Walter Porto Gonçalves ${ }^{46}$ tem dificultado a percepção de que, não raro o encaminhamento dado pelos organismos multilaterais aos problemas ambientais tem resultado na obtenção de mais poder de alguns sobre outros. Na primeira metade do século XX, a polêmica sobre a degradação do meio ambiente era destituída da força ideológica e da visibilidade global que tem hoje.

\section{Construindo a paisagem colonial}

Uma afirmação recorrente não apenas entre os historiadores ambientais é que a paisagem tem história. Em geral se tem denotado os processos de transformação dos elementos naturais ou das cicatrizes deixadas no espaço geográfico, nas árvores, no relevo, da fauna e flora, nos caminhos por antigos usos e modos de apropriação da natureza, revelando fisionomias pretéritas. Porém, não se problematiza a historicidade da ideia, ${ }^{47}$ desse modo de percepção dos elementos naturais que implica num conceito sobre o visualizado, numa organização e numa perspectiva. Muito menos de que paisagem, trata-se de uma conceptualização singular de algumas culturas que expressa seu modo singular, ou de alguns grupos hegemônicos dentro dela, de se relacionar com os elementos naturais e o espaço geográfico.

Vários autores têm apontado a questão da historicidade da paisagem, da percepção de alguns elementos naturais e das sensibilidades. A forma é considerada como dada, como natural, ela preexiste ao visualizado. O que possui história são os elementos culturais que se colam a essa imagem e às suas formas. Milton Santos não raro é lembrado por definir paisagem em distinção a espaço como um conjunto de formas. ${ }^{48}$ Porém, como apontou Anne Cauquelin, foi a pintura renascentista que começou a dar forma à nossa percepção da natureza. É nesse momento que se estabelece a janela que enquadra o visualizado, a perspectiva, a posição do observador, a horizontalidade, a dimensão, a escala e a direção. Enfim, a forma também é criada.

\footnotetext{
${ }^{46}$ PORTO-GONÇALVES, Carlos Walter. O desafio ambiental. Rio de Janeiro: Record, 2004.

${ }^{47}$ Uma exceção é: SCHWARCZ, Lilia Moritz. Paisagem e identidade. A construção de um modelo de nacionalidade herdado. Acervo. Rio de Janeiro, v. 22, n. 1, p. 19-52, jan/jul 2009.

${ }^{48}$ Por exemplo em: MENEZES, op. cit. p. 29-64.
} 
Nancy Stepan argumenta que a ideia de natureza tropical e, portanto, paisagem tropical, representada via um repertório de imagens (forma de organização do campo visual), foi criada após a era pós iluminista. Esse aspecto é importante de ser levado em conta quando da análise dos testemunhos que participam de contextos tão diversos quanto os séculos XVII e XIX e sua descrição do visualizado.

Alguns historiadores ambientais têm produzido pesquisas que avançam por períodos longos, de mais de um a dois séculos. ${ }^{49} \mathrm{O}$ primeiro livro no gênero publicado sobre o Brasil foi o de Warren Dean sobre a mata Atlântica. Numa história de longuíssima duração, estende-se do momento da entrada dos primeiros grupos humanos, por volta de 12000 anos antes de presente, à década de 1990, através de fontes primárias impressas e estudos recentes. Argumenta sobre o processo de destruição da floresta. Pouquíssimos tentaram proceder a um trabalho tão ousado. Tal periodização, entretanto, cria um problema quanto à análise dos testemunhos, caso se conceba a historicidade da ideia de paisagem e da sensibilidade frente aos elementos naturais.

Constatando que a ideia de paisagem foi criada como equivalente à natureza, Anne Cauquelin declara que: "temos a impressão de que a paisagem preexiste à nossa consciência, ou quando menos, que ela nos é dada "anteriormente" a toda cultura. Originária, a paisagem? Isso não seria confundi-la com aquilo que ela manifesta a seu modo, a Natureza?". ${ }^{50}$ Esse equivocado uso do termo para aludir a um conjunto de elementos naturais como se a sua unidade independesse do critério de homogeneidade determinado pela classificação criada pelo cientista ou pela visão do artista, como se fosse uma concretude, é muito comum nos estudos historiográficos, e particularmente associado à destoante afirmação de que se trata de uma palavra criada no século XV para reportar a um tipo de pintura. O grande problema é que a palavra paisagem faz parte de nosso cotidiano e a utilizamos como o visualizado e seu objeto, a própria natureza organizada. É difícil nos livrarmos desse hábito ordinário. Porém, essa desordem revela o poder do conceito, dando força às idealizações que se aderem a ele.

\footnotetext{
${ }^{49}$ Vale apontar:

CABRAL, Diogo de Carvalho. Na presença da floresta. Mata Atlântica e história colonial. Rio de Janeiro: Garamond; Faperj, 2014.

CORRÊA, Dora Shellard. op. cit.

DEAN, Warren. op. cit, 1995 PRESTES, Maria Elice Brzezinski. A investigação da natureza no Brasil colônia. São Paulo: Annablume; Fapesp, 2000.

${ }^{50}$ Vide:

STEWART, Pamela J.; STRATHERN, Andrew. Introduction. In: London: Pluto Press, 2003. p.1-15. Ed. Landscape, memory and history.
} 
A ideia de paisagem é apontada entre outros por Simon Schama, Alain Corbin, Denis Cosgrove, Jean Mac Besse, Barbara Bender e Raymond Williams ${ }^{51}$ como portadora de historicidade,$^{52}$ é, portanto, tempo e espaço. Denis Cosgrove ${ }^{53}$ mostrou que a noção vai se construindo a partir do século XV com o surgimento das pinturas de paisagem como uma extensão de terra que se visualizava de um ponto de vista externo. Alain Roger ${ }^{54}$ afirma que foi fundamental nesse processo de reprodução artística da natureza a dessacralização dos elementos naturais, que até o início do renascimento remetiam ao sagrado, e à sua organização numa unidade conceitual. Ulpiano Bezerra de Meneze ${ }^{55}$ acrescenta a importância da invenção da perspectiva para esse tipo de arte. Desenvolvendo-se, portanto, no contexto da transição para o capitalismo mercantil, com a laicização da cultura, o desenvolvimento das técnicas artísticas nas artes e na possibilidade objetiva de alguns homens e mulheres adotarem uma postura contemplativa e sensível em relação ao mundo externo natural e humanizado.

O crítico literário Raymond Willians em Campo e Cidade ${ }^{56}$ observou que $o$ ato de contemplar as formas e movimentos da terra e deles sentir prazer e tirar significados práticos e filosóficos deve ter acontecido em todos os tempos e entre todos os grupos sociais antes do Renascimento. Pesquisando como a literatura anglo saxônica, a partir do século XVI, refletiu sobre os modos de vida rural e urbano, apontou que, entre os séculos XVII e XVIII, um tipo peculiar de observador distinguiu as apreciações práticas das estéticas, a natureza da cultura. Foi nesse mesmo contexto que se inventou o termo "scenery", vista, e o ato de contemplar uma vista passou a ser consciente e externo à cena visualizada. Essa separação do observador em relação ao observado reflete a divisão entre trabalho e consumo.

\footnotetext{
${ }^{51}$ CORBIN, op. cit. COSGROVE, Denis E. Social formation and symbolic landscape. With a new introduction. Madison, The University of Wisconsin Press, 1998.BESSE, op. cit.

BENDER, Barbara. (Ed.) Landscape politics and perspectives. Oxford: Berg, 1993.

SCHAMA, op. cit. WILLIAMS, op. cit..

${ }^{52}$ Historicidade está sendo entendida aqui a partir de Agnes Heller: “A historicidade não é apenas alguma coisa que acontece conosco, uma era propensão, na qual nos 'metemos' como que veste uma roupa. Nós somos historicidade; somos tempo e espaço". Ou seja, o sentido dado ao termo ou ao seu conteúdo não é estático

${ }^{53}$ COSGROVE, op. cit.

${ }^{54}$ ROGER, Alain La naissance du paysage em Occident. In: SALGUEIRO, Heliana Angotti (org.). Paisagem e arte. A invenção da natureza, a evolução do olhar. São Paulo: CBHA/CNPQ/Fapesp, 2000. p. 163-170.

${ }^{55}$ MENEZES, op. cit.. p. 29-64

${ }^{56}$ WILLIAMS, op. cit.
} 
Williams afirmou que vivemos num mundo em que os próprios modos de percepção e de ação distanciados, separados e externos são frutos de uma imposição política, de um modo de produção e de suas relações sociais dominantes. Só conseguimos chegar às deformações processadas por essa forma de percepção quando deixamos de nos colocar externamente, separados e distanciados do mundo e de nosso objeto. Só superaremos a divisão, ultrapassando a divisão do trabalho, caminhado pela experiência.

Ao final do século XIX, a Geografia apropriou-se do termo paisagem para evidenciar a relação do homem com a natureza, que poderia ser empiricamente e objetivamente apreendida e estudada por métodos científicos. Cosgrove afirma que, apesar das tentativas de se dar maior objetividade ao conceito, para servir como um instrumento científico, não se pode apagar esse passado ligado ao subjetivo e ao sublime que marcava as pinturas. Conforme esse autor a paisagem expressa um modo de ver o mundo: "uma maneira que alguns europeus representaram a eles mesmos e os outros, o mundo ao redor deles e sua relação com esse mundo através do qual eles justificam as relações sociais". ${ }^{57}$ Revela um modo de apropriação da Terra, reforçando um modo de percepção do espaço.

Cosgrove e Williams ${ }^{58}$ discutem paisagem a partir de uma bibliografia e fontes que poderíamos caracterizar como "eruditas", pintores, literatos e cientistas que tinham uma atividade profissional que possibilitava que se distanciassem da cena retratada. Essas obras têm como objetivo deleitar, sensibilizar e estimular intelectualmente o seu público. Grupos que crescem a partir do Renascimento e do processo de urbanização, estimulado pelo capitalismo nascente. Esses testemunhos com os quais desenvolvem sua pesquisa, bem como os que Simon Schama, Keith Thomas, Alain Corbin ${ }^{59}$ e uma parte expressiva dos historiadores brasileiros que trabalham com paisagem, são semelhantes e expressam, segundo todos esses intelectuais sugerem, um modelo de visão "ocidental" da natureza. Suas raízes assentam-se na Europa “ocidental” (Inglaterra, França, Alemanha, Holanda, Itália, Portugal, Espanha). Esse modo de retratar o visualizado, segundo eles, legitima uma relação de poder, é imposto por uma classe social sobre as demais e, a partir do

\footnotetext{
${ }^{57}$ COSGROVE, op. cit., p. 1.

${ }^{58}$ Ibidem.

WILLIANS, op. cit.

${ }^{59}$ CORBIN, , op. cit.

SCHAMA, op. cit.

THOMAS, op. cit. .
} 
século XVI, primeiro às colônias americanas, depois à Oceania, África e Ásia no século XIX.

Como apontei, a historiografia brasileira tem pesquisado documentos elaborados por pintores ou por cronistas, clérigos, viajantes, cientistas, pessoas socialmente e culturalmente semelhantes e, especialmente, que se colocam numa mesma posição externa à cena retratada. Contudo, não se sabe como essas matrizes de descrição foram assimiladas fora da literatura, das artes e da ciência no Brasil até o século XIX, num momento em que o letramento ainda não era universal, e por aqueles homens que estavam experimentando diretamente a natureza que descreviam, na qual estavam inseridos, informando seu comandante, filho, amigo sobre o roteiro a ser seguido para não se perderem nas matas ou evitarem locais de febres ou territórios de índios inimigos. Ou mesmo, que estavam justificando uma ação ou a posse de terras.

Alguns intelectuais ${ }^{60}$ preocupados em justificar que o termo paisagem não pode ser reduzido a uma representação do visualizado, afirmam que a referência a uma exterioridade concreta está na sua base. Lembram que em várias línguas da Europa ocidental em que se origina a palavra paisagem, ela tem em sua raiz o termo terra e país Land/ladschaft na Alemanha, Land/ landscape na Inglaterra, pay/paysage na França, paese/paesaggio na Itália, país/paisagem em Portugal. Defendem que a origem do conceito na arte que busca reproduzir o visualizado, remete tanto a uma concretude e forma, os elementos da natureza visualizados, como ao subjetivo. Negam a definição de paisagem unicamente como um fato cultural. Essa ligação do conceito com terra e país explica a facilidade com que se associou recorrentemente determinadas paisagens ao sentimento de pertencimento a uma dada unidade política territorial. Esse é o argumento de Simon Schama em Paisagem e Memória. Esse é um dos assuntos mais explorados pela historiografia brasileira que discute paisagem dentro da história cultural.

Ulpiano Bezerra afirma o caráter histórico da paisagem. Segundo ele:

A paisagem tem história. Não nos referimos, é claro, ao fato elementar de que submetida a constantes processos de transformações - como tudo mais na natureza - a paisagem não é estável, mas dinâmica. Mas, deixando de lado as escalas geográficas de tempo ou a ocorrência, na escala do tempo humano, de episódios naturais dramáticos e, por outro lado, considerando homem e paisagem como indissociáveis, podemos afirmar que a paisagem tem história, que ela pode ser objeto de conhecimento histórico e que essa história pode

${ }^{60}$ Por exemplo: BESSE, op. cit. .ROGER, op. cit., p. 163-170. 
ser narrada (...) A paisagem oferece pistas materiais que permitem perceber seu caráter histórico. ${ }^{61}$

Nessa passagem, o historiador está considerando paisagem como uma concretude, semelhante à natureza. Resume o seu caráter histórico às interferências da natureza, nos elementos naturais que apresentam vestígios de outros tempos. Anne Cauquelin, diferentemente desses intelectuais que defendem a historicidade da paisagem e que a restringem as interferências no espaço geográfico, aí denotando um objeto, lembra-nos que paisagem é uma imagem, portanto, com formas, enquadramento, distância, orientação, pontos de vista, situação de escala, medidas e as nossas percepções definidas culturalmente. Assim ao postular a historicidade do quadro como um todo, de suas formas percebidas, da escala apresentada, do ponto de vista e do conjunto, e não a mudança da natureza que não pode ser confundida com natureza.

Se Cosgrove e Williams ligam a genealogia da ideia de paisagem ao desenvolvimento do capitalismo mercantil e à imposição por uma classe social sobre as demais de sua forma de olhar a natureza como universal, Anne Cauquelin mostra como a força dessa imposição é mais forte e sutil do que em geral imaginamos, não se restringe ao pensamento, avança pelo ato de compreender e configurar o material discernido pelos olhos. Polemiza que foi na construção da ideia de paisagem que se deu uma "forma, um enquadramento, medidas a nossas percepções". ${ }^{62}$ A própria forma apreendida é uma construção cultural. Ou seja, a pintura foi conformando a nossa conscientização e assimilação dos elementos naturais que organizamos num quadro, numa paisagem. Permanentemente estamos sendo educados no modo de ver e de sentir a natureza pela escola, pintura, cinema, fotografia, meios digitais e etc.

Dialogando com eles, Barbara Bender, ${ }^{63}$ arqueóloga inglesa, critica a informação implícita em estudos sobre a origem da categoria paisagem, que indicam sua invenção pelos europeus do oeste - particularmente italianos, flamengos, ingleses, franceses e alemães - e que, portanto, fazem crer que somente eles desenvolveram uma relação cognitiva com a natureza. Declara que todos os povos do mundo estabelecem reflexões sobre sua relação com o

\footnotetext{
${ }^{61}$ MENEZES, op. cit.. p. 36.

${ }^{62}$ CAUQUELIN, op. cit. .

${ }^{63}$ BENDER, op. cit,.

BENDER, Barbara; WINER, Margot (Eds.) Contested landscapes. Movement, exile and place. Oxford: Berg, 2001.
} 
espaço físico. Contudo, nem todos se preocupam em criar um conceito para designá-las.

Reconhece, acompanhando Denis Cosgrove, que aquela forma de percepção do espaço, imposta a partir do século XV no oeste da Europa, reflete o domínio de uma classe sobre as demais. Entretanto, considera que ter a classe social como foco único de atenção é um critério redutor da realidade. Assim como, leva ao silenciamento e ao ocultamento de muitos, daqueles que vivem à margem da sociedade e que pertencem a uma etnia ou a um gênero submetido dentro da própria classe.

Barbara Bender fragmenta o social em etnia, gênero, idade e critica as teorias que reduzem a realidade. Mas, segundo a antropóloga, classe já é uma fragmentação. Mary Louise Pratt em Os olhos do Império, não negando que homens e mulheres que viajaram pelo globo a serviço da Inglaterra no século XIX partilhavam de um mesmo substrato cultural, ou seja, sem fugir à fixação de um quadro geral sobre as representações europeias da América e da África, apresenta as peculiaridades dos olhares por gênero, possibilitando uma visão mais detalhada daquelas sociedades coloniais.

Paisagem, afirma Bender, ${ }^{64}$ é tempo e espaço. Seu estudo tem que ser contextualizado uma vez que o modo pela qual as pessoas concebem e se relacionam com a Terra varia ao longo do tempo, do espaço e das condições históricas particulares em que se encontram. Relaciona-se, portanto, também à sua situação econômica, seu gênero, idade e classe.

A antropóloga inglesa nos atenta para o fato de que na cultura ocidental paisagem está associada ao visual. Como entende que paisagem é o processo de relação dos homens e mulheres com o meio ambiente, indica que outras culturas, embora não tenham um termo como paisagem, relacionam-se com a natureza e de inúmeras maneiras, pelo olfato, pela audição e etc. Também a memória, as lembranças fazem parte das paisagens. Elas são levadas nas migrações e depois transplantadas, adequadas ou guardadas.

Cosgrove e Williams estão discutindo a paisagem como o visualizado, que pode, no caso do segundo, ser uma memória em imagem que é reavivada por outros sentidos, ou conscientemente preservada como um elemento da identidade por um observador, argumentando que ela contém muito mais do que somente o real concreto enxergado. Concordam que as relações dos homens e mulheres entre si e deles com a natureza marcam concretamente a terra. Porém, a forma pela qual nós apreendemos essa relação - pela visão,

${ }^{64}$ BENDER, 2001. 
localizados externamente ao observado e utilizando uma metodologia que valida o caráter objetivo do percebido - é parte de uma estratégia de dominação. Assim a ideia de paisagem que se revela numa prática de relação com o mundo dissimula seu caráter político.

Bender está pensando a produção do espaço em termos materiais e abstratos que se reconhece através do trabalho de campo e da descrição e interpretação etnográfica, especialmente de sociedades à margem do capitalismo. Daí sustentar que a crítica à ideia de paisagem feita por Cosgrove, Williams e outros têm no horizonte sociedades urbano industriais. Ela não é suficiente para revelar e qualificar a diversidade de formas de relações com a terra existentes no globo. Muito menos permite que se evidenciem os nexos de poder dentro das classes hegemônicas. Enfim, as críticas que universalizam as realidades observadas nos países centrais do capitalismo e que colocam a classe como categoria fundamental de análise, segundo ela, são redutoras da realidade, inviabilizam a apreensão das diversidades e singularidades existentes no mundo hoje.

A desconsideração, portanto, da diversidade de formas de produção do espaço ou a relação com ele no interior da própria Europa ocidental, onde o termo paisagem foi inventado, implica no ocultamento de inúmeros sujeitos históricos e, não raro, como aconteceu no Brasil com os índios, na sua naturalização. Tal constatação permite que se problematizem as descrições de territórios indígenas produzidos por cronistas, técnicos e outros e sua releitura pela historiografia que hoje, com menos intensidade, ainda afirma a virgindade desse território, naturalizando-o.

Denis Cosgrove, Raymond Williams, Barbara Bender e Anne Cauquelin auxiliam a refletir sobre a ideia de paisagem. Informam sobre como foi sendo construída no oeste da Europa, no contexto de desenvolvimento do capitalismo, e o seu papel como instrumento de poder. Destacam que o que lhe dá força é a visibilidade, mas também é o que cria a sua ambiguidade, a confusão entre os elementos naturais intelectualmente uniformizados, organizados e territorializados e a natureza. É também a visibilidade, contraditoriamente, que possibilita a deformação do mundo material, porque depende da subjetividade, de uma predisposição do sujeito da ação para ver, conforme Agnes Heller. ${ }^{65}$

${ }^{65}$ HELLER, op. cit. 


\section{Considerações finais}

Diferentemente de 1959, quando Sérgio Buarque de Holanda publicou Visão do Paraíso, hoje, em pleno novo milênio, a visão de parte do Brasil como paraíso terreal ainda persiste, contudo, num contexto diverso daquele. Observa-se um retorno dos historiadores à geografia e dos geógrafos à história. Se até as décadas de 1950 e 1960, a descrição da paisagem estava atrelada especialmente à concepção de Brasil e de brasileiros ${ }^{66}$ que se queria impor, hoje o retorno à paisagem num quadro de dilatamento dessa noção e de sua identificação com meio ambiente físico, numa conjuntura de crescente preocupação ecológica, de mercantilização da natureza visualizada e de um incrível incremento tecnológico, implica que a tratemos com maior cuidado. Segundo Anne Cauquelin, essa noção tem um papel importante de "formar e de garantir os quadros de uma percepção comum. Muito mais que um 'rótulo' estético, a paisagem confere uma unidade de visão às diversas facetas da política ambiental (...) Reassegurar permanentemente uma visão de conjunto, composta, enquadrada". ${ }^{67}$

A historiografia tem problematizado a transformação das formas de exploração e apropriação da natureza, bem como as descrições dos testemunhos e o que elas contêm além do concreto, as mudanças da sensibilidade frente a determinados conjuntos naturais e a própria ideia de natureza. Não se polemizou ou se teve como hipótese, entretanto, a historicidade da percepção das formas dos elementos naturais. O que se tem explorado são as ideias, o que se acrescenta ao real percebido, ocultando, revelando ou deformando-o.

Afirmar que paisagem tem história diverge de se dizer que a ideia de paisagem tem historicidade. São paisagens distintas. A primeira inspira ser um conjunto análogo à natureza, um objeto, e a segunda é uma abstração. Meu objetivo inicial com este artigo era instrumentalizar-me para elaborar uma história da paisagem de uma dada região do sul do Brasil, partindo do final do século XVII até o início do século XIX e polemizar sobre a ocupação e exploração das zonas de fronteira. No entanto, o percurso feito me mostrou que para chegar a esse conjunto de elementos naturais percebidos e artificialmente organizados, relacionados num conjunto, enxergados de um dado ponto, enquadrados e denominados, seja pelos meus testemunhos ou por eu

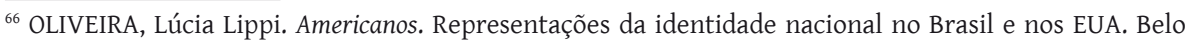
Horizonte: Humanitas, 2000.

${ }^{67}$ CAUQUELIN, op.cit, p. 10-11
} 
mesma, há de se desmistificar a naturalidade desse cenário e de sua percepção e de enfocá-lo como um processo no tempo e no espaço.

Neste artigo, parto da concepção que paisagem não é uma coisa, uma concretude, mas a visualização, organização, perspectiva e dimensionamento de elementos naturais visualizados. Embora uma parte do que compõe o visualizado sejam concretudes, mas não passam de árvores, rios, montanhas, praias. É o testemunho ou o pesquisador que cria o conjunto, que dá unidade e sentido a ele, que determina e descreve uma paisagem.

Assim, a crítica ao testemunho, não só os clássicos procedimentos de se contextualizar o documento e seu autor, envolve examinar especialmente o que lhe era sensível não apenas pelos olhos e o que não era e que hoje temos como visível. Como organizava os elementos naturais e humanos, de onde observava, a amplitude do visualizado, e a perspectiva. Devemos desconsiderar a forma como um objeto a-histórico. Como foi registrado no início deste artigo, a historiografia atual considera a historicidade das representações da natureza visualizada embutida na ideia de paisagem. Entretanto, como na sua grande maioria esses trabalhos abordam períodos de tempo em que são pouco perceptíveis as mudanças na consciência que se tem sobre o mundo natural e suas formas, além do que seu objetivo, nesse caso, não é trabalhar com a mudança.

Levar tais aspectos em consideração significa rever nossas discussões sobre a natureza brasileira, especialmente quando adotamos uma periodização longa. Investigar as descrições de paisagens da América portuguesa ao Brasil República, analisando ao mesmo tempo testemunhos oriundos de formações e de classes sociais diversas, que tinham objetivos diferentes, alguns com uma visão da natureza ainda não de todo laicizada e descolada da tradição e outros que traçaram formas que facilmente identificamos hoje, é uma empreitada complexa. Mais ainda se levarmos em conta que as interferências indígenas na natureza nos foram relatadas por informantes não índios. Dependemos, portanto, da sua predisposição para ver os elementos naturais, bem como da sua capacidade de distinguir vestígios das práticas indígenas.

Reconhecer que paisagem tem história implica em investigar o quadro como um todo, as formas, a perspectiva e etc. Criticar o testemunho para chegar aos seus limites perceptuais, o que ele oculta porque não vê ou porque não quer ver e aquilo que ele revela. Só então terei condições para inferir sobre os recursos naturais existentes e os vestígios de usos pretéritos.

A história natural pode descrever quais espécies existiam em dado local ou região ao longo de um tempo a partir de dados ecológicos/geográficos 
e biológicos. Organizá-los num conjunto, dimensioná-los, estabelecer uma perspectiva, enfim, imaginar paisagens. Porém, sem a análise das representações humanas, sejam fotografias, pinturas, números e documentos escritos, pouco se poderá inferir sobre as relações dos homens e mulheres com a natureza, relações estas que são tanto materiais como abstratas. E assim fugir às mistificações promovidas pela ideia de que paisagem é um objeto e a projeção de representações do presente sobre o passado. Discutir a crítica a essa documentação é o caminho para se produzir pesquisas que possibilitem entrever realidades pretéritas ou a elaboração de representações que promovam a desmistificação da memória.

Artigo recebido para publicação em 13/10/2015

Artigo aprovado para publicação em 30/11/2015 